\title{
Schwanenblume (Butomus umbellatus), Blume des Jahres 2014
}

Kurt Baumann

\begin{abstract}
Grass rush (Butomus umbellatus) ist flower of the year 2014. Morphology, ecology and ethymology of the species are outlined.
\end{abstract}

Zusammenfassung

Die Schwanenblume (Butomus umbellatus) ist Blume des Jahres 2014. Ihre Morphologie und Ökologie sowie die Namensherkunft werden beschrieben.

\section{Vorkommen und Verbreitung}

Die Schwanenblume (Butomus umbellatus, Butomaceae) wurde von der Loki Schmidt-Stiftung zur Blume des Jahres 2014 gewählt. Sie ist eng mit den Froschlöffelgewächsen (Alismataceae) verwandt. Froschlöffel- und Schwanenblumengewächse sind mit 7 weiteren Familien in der Ordnung der Alismatales vereinigt. Die Schwanenblume ist in Schleswig-Holstein (nicht im Innern im Geestgebiet), Niedersachsen, Bremen, Hamburg und Mecklenburg-Vorpommern weit verbreitet. Im Süden und in der Mitte Deutschlands folgt sie dem Verlauf der großen Stromtäler (Betinger 2013).

Die Schwanenblume ist eine Wasserpflanze, die in flachen, stehenden oder langsam fließenden Gewässern wie Sümpfen, Gräben, Tümpeln, Seen und Flüssen an den Ufern verbreitet ist. In schnell fließenden, tiefen Gewässern tritt sie nur als flutende, nicht blühende Pflanze mit bandförmigen Blättern auf (Düll \& KutzeLNIGG 2011). Sie wächst in basen- und nährstoffreichem, meist kalkreichem Wasser auf schlammigem oder sandig-kiesigem Boden. Sie ist wärmeliebend, erträgt mäßige Verschmutzung und ist gegen Schwankungen des Wasserstandes wenig empfindlich. Lockere Bestände bildet sie in Wassertiefen bis $0,5 \mathrm{~m}$, wo sie optimal wächst. Pflanzensoziologen fassen diese Bestände als eigene Pflanzengesellschaft auf (Butometum umbellati). In der Pfeilkraut-Igelkolben-

Abb. 1: Größerer Bestand der Schwanenblume (Butomus umbellatus).

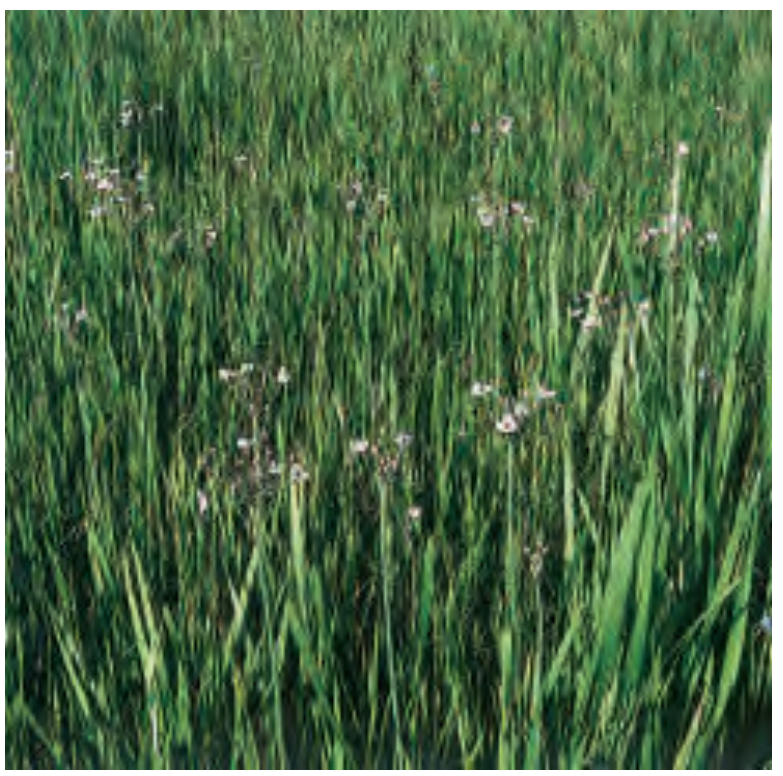

Gesellschaft, bei der es zu Wassertiefen bis 1,7 m kommt, bleibt die Schwanenblume auch im langsam durchströmenden Wasser steril.

Verständlich, dass die Schwanenblume in den wasserreichen Tiefländern Deutschlands mit zahlreichen Seen und vielen Gräben nicht selten ist, während sie in den Alpen fehlt. Allerdings dringt sie seit ungefähr 1905 in Schweizer Flüssen rasch vor. Davor zeigte das Areal einen Ring um die Alpen (Marrkgraf 1980).

Die Gesamtverbreitung der Schwanenblume erstreckt sich fast über ganz Europa bis in das gemäßigte Asien. Von manchen werden die dort vorkommenden Pflanzen als Varietät behandelt. Außer Sardinien hat Butomus umbellatus keine der größeren europäischen Inseln erreicht. Sie fehlt auf den Azoren, Balearen, Färöern, Island, Korsika, Kreta, Sizilien und Spitzbergen. Die Südgrenze ihres Vorkommens verläuft von Thrakien, Thessalien, Makedo- 

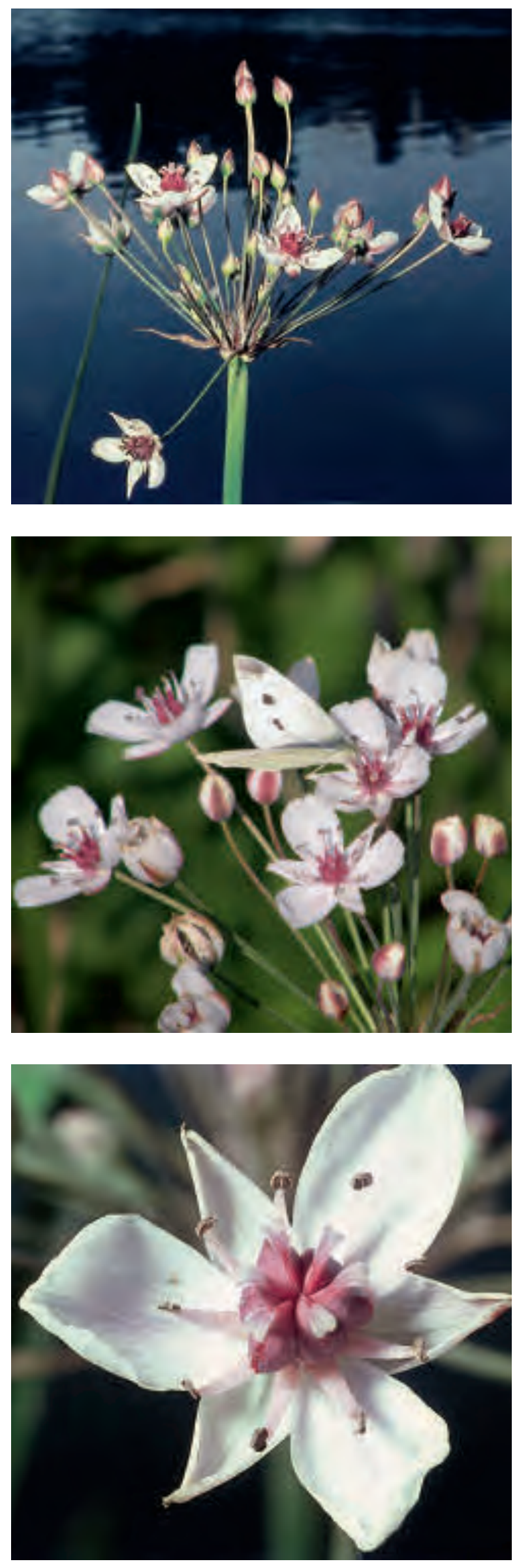

nien, Epirus, Süditalien, Sardinien über Katalonien bis Mittelportugal. Im Norden erstreckt sich ihr Areal von Irland über England und Schottland nach Jütland, Lappland und NordRussland. In Asien kommt die Schwanenblume vom Amur-Gebiet bis zum Jenissei vor, in einem Streifen durch West-Turkestan nach NordIran bis Kleinasien und zum Kaukasus.

In Nord-Amerika ist sie nach Einführung durch den Menschen eingebürgert. Da die Schwanenblume als Zierpflanze kultiviert wird, sind viele Vorkommen an Tümpeln und Teichen wahrscheinlich auf Anpflanzung zurückzuführen und keine ursprünglichen Vorkommen. Die natürlichen Bestände sind in Deutschland nicht gefährdet. Sie wird deshalb auf keiner Roten Liste geführt. Treten Rückgänge auf, sind dies Folgen von Gewässerausbau, vielleicht in einigen Fällen auch vom Abfressen durch Bisamratten.

\section{2. Äußeres Erscheinungsbild}

Die Schwanenblume ist eine mehrjährige Rhizomstaude. Das etwa $1 \mathrm{~cm}$ dicke Rhizom wächst kriechend waagerecht. An seiner Spitze trägt es eine vegetative Endknospe. Unterseits entspringen dünne Nährwurzeln sowie dicht quer gerunzelte Zugwurzeln, die das Rhizom in die richtige Tiefe ziehen. Auf der Oberseite entwickeln sich die Blätter. In ihren Achseln bilden sich Seitenknospen, jede neunte mit einem Blütenstand. Gelegentlich entstehen in den Blattachseln Brutknöllchen, die abfallen und für eine vegetative Vermehrung sorgen. Das Rhizom enthält bis $60 \%$ Stärke und wird in Teilen Asiens als Nahrungsmittel benutzt.

Die Blätter sind linealisch und werden rund $1 \mathrm{~m}$ lang bei einer Breite von $6-8 \mathrm{~mm}$. Sie sitzen mit breiter, umfassender Scheide zweizeilig am Rhizom. Sie sind dreikantig, stehen auf-

Abb. 2 (oben): Doldiger Blütenstand der Schwanenblume. Abb. 3 (Mitte): Schwanenblume mit Kohlweißling in einem feuchten Graben in Lilienthal bei Bremen.

Abb. 4 (unten): Nahaufnahme einer Blüte der Schwanenblume. 
recht oder sind flutend. Das Blattinnere wird von vielen Luftkanälen durchzogen, die durch einschichtige Längs- und Querplatten voneinander getrennt sind. In diese Platten sind unregelmäßig die Leitbündel eingebettet (MARKGRAF 1981). Die entfalteten Laubblätter ordnen sich gruppenweise dicht um einen Blütentrieb. Pro Jahr entstehen 2-3 Blattgruppen.

\section{Blüte und Frucht}

Der Blütenstand ist $1,5 \mathrm{~m}$ lang gestielt. Er ist doldenähnlich, aber keine echte Dolde. Der Blütenstand ist aus bis 30 Einzelblüten zusammensgsetzt (Philippi 1998). Eine Endblüte ist vorhanden. Sie wird von 2-4, meist 3 Schraubeln (Cymen) mit ungleich lang gestielten Blüten umgeben (Wagenitz 1996, Schubert \& Wagner 2000). Die Einzelblüte der Schwanenblume ist radiär, zwittrig und selbststeril. Die Blütenhülle besteht aus sechs eiförmigen, gewölbten Perigonblättern. Diese sind um die $15 \mathrm{~mm}$ lang, die drei äußeren $8 \mathrm{~mm}$, die drei inneren $15 \mathrm{~mm}$ breit. Sie sind rosa bis weiß gefärbt und dunkel geadert (Heywodd 1982). Die Staubblätter mit den roten Staubbeuteln sind halb so lang wie das Perigon. Sie stehen in zwei Kreisen, sechs vor den äußeren, drei vor den inneren Blütenblättern.

Die 6 (-9) roten, oberständigen Fruchtblätter sind nur am Grund verwachsen. Sie sind mit $1 \mathrm{~cm}$ Länge ungefähr so lang wie die Staubblätter. Ihre Gestalt ist flaschenförmig. Die Narben heben sich durch ihre weiße Farbe ab. Die Samenanlagen liegen zahlreich an der Innenseite außer der Mittelrippe und den Rändern. Zwischen den Fruchtblättern wird wie bei Liliengewächsen Nektar in Septalnektarien ausgeschieden. Es sind dann sechs Tröpfchen $\mathrm{zu}$ beobachten. Besucht werden die angenehm nach Honig duftenden Blüten von Bienen, Hummeln, Schwebfliegen und Schmetterlingen. Die Blüten sind vormännlich, d.h. die Staubgefäße reifen vor den Fruchtblättern.

Die Früchte sind reif verkehrt-eiförmig und werden von der bleibenden Narbe gekrönt. Es sind Balgfrüchte, die sich an der Bauchnaht öffnen und die länglichen Samen entlassen. Die nährgewebsfreien, leichten Samen werden durch den Wind ausgeschleudert, aber auch über Wasser ausgebreitet. Zum Keimen benötigen sie einen Kältereiz.

\section{Namen und Einordnung}

Der Name Schwanenblume wurde 1839 veröffentlicht. Mundartlich ist er aus den Vierlanden bei Hamburg bekannt. Andere deutsche Bezeichnungen sind Wasserliesch, Blumenliesch oder Blumenbinse. Der Name Liesch bedeutet im Mittelhochdeutschen Riedgras. Um 1600 wird die Schwanenblume als blühende Binse bezeichnet.

Niederdeutsche weitere Volksnamen sind u. a. Adebarsblom (vermutlich entsprechend der Schwanenblume wegen des langen Stängels), Wasserblom, Henn un Küken (möglicherweise weil die Frucht von Perigonblättern umgeben ist), Koffjeblom (vielleicht wegen der bräunlichen Knospenfarbe). Die wissenschaftliche Bezeichnung Butomus wurde Ende des 16. Jh. von der griechischen Bezeichnung einer Sumpfpflanze mit schneidenden Blättern übernommen (bous = Rind; tomein=schneiden, GENAUST 2005). Die schneidenden Blätter kommen aber bei der Schwanenblume gar nicht vor. Der Name würde besser für die Segge Cladium mariscus mit ihren scharfen Blatträndern passen, die auch im Deutschen Schneide heißt. Der Artbeiname umbellatus bedeutet doldig und bezieht sich auf den Blütenstand.

\footnotetext{
Literatur

Bettinger, A, Caspari, S \& Klotz, J. 2013: Verbreitungsatlas der Farn- und Blütenpflanzen Deutschlands. Bonn.

Düll, R. \& Kutzelnigg, H. 2011: Taschenbuch der Pflanzen Deutschlands. 7. Aufl. - Wiebelsheim. Genaust, H. 2005: Etymologisches Wörterbuch der botanischen Pflanzennamen. 3. Aufl. - Hamburg. Heywood, V. H. 1982: Blütenpflanzen der Welt. - Basel. Markgraf, F. 1981: Familie Butomaceae - Schwanenblumengewächse. In Conert, H. J.(Hrsg.): Hegi, Illustrierte Flora von Mitteleuropa. Bd. I 2. 3. Aufl. - Berlin. Philippi, G. 1998: Butomaceae - Blumenlieschgewächse. In Sebald, O., Seybold, S. \& Philippi, G.: Die Farn- und Blütenpflanzen Baden-Württembergs. Bd.7. - Stuttgart. Schubert, R. \& Wagner, G. 2000: Botanisches Wörterbuch. 12.Aufl. - Stuttgart.

WAGENITZ, G.1996: Wörterbuch der Botanik. - Jena.
} 